\title{
Pedestrian navigation using the sense of touch
}

\author{
Ricky Jacob $^{\mathrm{a}, *}$, Adam Winstanley ${ }^{\mathrm{a}}$, Naomi Togher ${ }^{\mathrm{b}}$, Richard Roche ${ }^{\mathrm{b}}$, Peter Mooney ${ }^{\mathrm{a}}$ \\ ${ }^{a}$ Department of Computer Science, National University of Ireland Maynooth, Co. Kildare, Ireland \\ ${ }^{\mathrm{b}}$ Department of Psychology, National University of Ireland Maynooth, Co. Kildare, Ireland
}

\section{A R T I C L E I N F O}

\section{Article history:}

Available online 6 November 2012

\section{Keywords:}

Haptics

Pedestrian navigation

Orientation

Memory recall

Cognition

Spatial abilities

\begin{abstract}
A B S T R A C T
Haptics is a feedback technology that takes advantage of the human sense of touch by applying forces, vibrations, and/or motions to a haptic-enabled user device such as a mobile phone. Historically, human-computer interaction has been visual, data, or images on a screen. Haptic feedback can be an important modality in Mobile Location-Based Services like - knowledge discovery, pedestrian navigation and notification systems. In this paper we describe a methodology for the implementation of haptics in four distinct prototypes for pedestrian navigation. Prototypes are classified based on the user's navigation guidance requirements, the user type (based on spatial skills), and overall system complexity. Here haptics is used to convey location, orientation, and distance information to users using pedestrian navigation applications. Initial user trials have elicited positive responses from the users who see benefit in being provided with a "heads up" approach to mobile navigation. We also tested the spatial ability of the user to navigate using haptics and landmark images based navigation. This was followed by a test of memory recall about the area. Users were able to successfully navigate from a given origin to a Destination Point without the use of a visual interface like a map. Results show the users of haptic feedback for navigation prepared better maps (better memory recall) of the region as compared to the users of landmark images based navigation.
\end{abstract}

(ㄷ) 2012 Elsevier Ltd. All rights reserved.

\section{Introduction}

Conventional pedestrian navigation applications present the user with position and orientation details through visual modalities such as a map with various layers of information. Generally, the shortest pedestrian route is overlaid on the map. Text-based turn-by-turn instructions are also provided. Strachan, Eslambolchilar, Murray-Smith, Hughes, and O'Modhrain (2005) give examples of pedestrian navigation with audio feedback. In-car navigation systems ('sat-nav') provide a turn-by-turn audio assistance combined with a map display. Wikitude (2012) have recently developed a complete augmented reality in car navigation application. Wikitude list a key advantage as not requiring "the users to take their eyes off the road" which is not the case with traditional car navigation systems. Obviously the driver must be alert at all times while operating a vehicle on public roads. Similarly it is also important that pedestrians are attentive to their physical environment. Rather than being engrossed in their mobile device they must pay attention to dangers, such as: physical obstacles, other pedestrians, and road traffic. Unlike the protected environment of a car, the current context, both physical and social, of a pedestrian may

\footnotetext{
* Corresponding author.

E-mail addresses: rjacob@cs.nuim.ie (R. Jacob), adam.winstanley@nuim.ie (A. Winstanley), naomi.togher.2010@nuim.ie (N. Togher), richard.roche@nuim.ie (R. Roche), peter.mooney@nuim.ie (P. Mooney).
}

not be suitable for them to continuously interact with the mobile device. In these contexts a non-obstructive mode of communication like haptics appears to be a very suitable alternative to text or map-based feedback.

Haptic feedback or "haptics" is a technology that provides forced feedback, vibrations, and/or motions users using a device (Jacob, Mooney, Corcoran, \& Winstanley, 2010). Haptics relies on the human sense of touch and recently has begun to appear in a broad range of research and applications (Amemiya, Ando, \& Ando, 2008; Hoggan \& Brewster, 2010; Paneels \& Roberts, 2010; Pascale, Mulatto, \& Prattichizzo, 2008; Williamson et al., 2010). Examples include: performing a robot-assisted endoscopic surgery (Tavakoli, Patel, \& Moallem, 2005), assisting visually impaired people to navigate and explore a simulated 3D environment (Pascale et al., 2008), and most prominently in computer game consoles. Jacobson (2002) provides a good overview of the accessibility and usability issues in representing spatial information through multimodal interfaces using visual, audio, and haptics modes. Haptic feedback has been used in various other systems like alerting passengers using public transport about the arrival at the destination bus stop to help them prepare for disembarking (Jacob, Shalaik, Winstanley, \& Mooney, 2011).

There has been some debate over how humans recall information after navigating environments, with accounts including egocentric and allocentric elements, as well as incorporating route and survey-based information (Roche, Mangaoang, Commins, 
\& O’Mara, 2005). Humans require certain spatial strategies in order to navigate their environment - including a mental representation of the area that they are navigating and the ability to determine a suitable route to explore the environment (Tversky, 2000). Kuipers (1978) finds that those with detailed cognitive maps of an area can orient themselves by local features of each place in the street network. Kuipers also adds that such people can often have a sufficient stock of familiar routes that they need not maintain a two-dimensional orientation at all, but can just follow route descriptions. Cognitive functions that enable people to deal effectively with spatial relations, visual spatial tasks and orientation of objects in space is defined as spatial abilities. One aspect of these cognitive skills is spatial orientation, which is the ability to orient oneself in space relative to objects and events; and the awareness of self-location (Sjölinder, 1998).

In this paper we present pedestrian navigation using haptic feedback as the modality to represent spatial information such as location, distance, and orientation. We demonstrate how navigation instructions can be provided to the user by describing four prototypes where the vibration alarm (with varying frequency and pattern) is used to convey navigation instructions. We find that it is easy/faster to help users orient themselves in space while using haptics for navigation assistance especially in orientation is the real-world. Thus, we see that haptic feedback can be used as a modality to deliver information in a wide variety of systems when it is inappropriate to use other modalities like vision and audio. From the overall navigation guidance using haptics, the users can expect subtle feedback for assistance which ensures low attentiveness from the user while on the move.

We report on the tests carried out to see if users can successfully navigate from the origin to the destination without the use of visual cues like a list of landmark images along the way or a panoramic view of the destination. Information extracted from largescale external environments and stored in human memory exists in some type of psychological space (Golledge, 1999). Golledge adds that it is reasonable to assume that as environmental learning occurs, some of the standard geometry of identifiable physical space will be included in its cognitive representation. We thus test the spatial abilities and memory recall of the user by recreating a map of the region on paper based on memory recall after the navigation task.

This paper is organised as follows. Section 2 provides motivation for the research and an overview of the relevant literature in the field of haptics with emphasis on existing GIS and pedestrian navigation applications. Integration of haptics in pedestrian navigation systems is discussed in Section 3. Our haptic interaction model for pedestrian navigation applications is described in detail in Section 4. Descriptions of the four distinct pedestrian navigation prototypes are also provided. Section 5 describes the experimental setup and the results and key findings from the experiments are listed in Section 6. The paper closes with Section 7 with the key outcomes from the paper and discussion of the future direction of this research.

\section{Motivation and overview of related work}

Erp (2001) argues that current popular navigation techniques for pedestrian navigation applications are not reasonable or possible at all times. Interacting with the map display on a mobile device means that the user has a "neck-down" approach. The user uses one hand to hold the device and the other to interact with the user interface. The range of interaction includes zoom, pan, and click. During this time the user's attention, while interacting with the map interface, is almost entirely on the device and they are potentially unaware of any physical dangers or obstacles around them. Robinson, Jones, Eslambolchilar, Smith, and Lindborg (2010) argues that the interactions users have with their environment must always be considered more important than interactions they are having with the mobile device interface.

Moussaid, Perozo, Garnier, Helbing, and Theraulaz (2010) found that about $70 \%$ of people on a crowded street are actually moving in a smaller group potentially friends or family. The requirement for continuous interaction with the mobile interface means that the user is not able to: interact with that group, carry items in their hands, etc. Some attempts have been made to deal with these issues. In Holland, Morse, and Gedenryd (2001) the authors present a backpack mounted AudioGPS providing audio feedback to the user to help in navigation. The drawback with such an application is the need for the user to have their sense of hearing fully involved to understand the feedback along with the requirement to carry the backpack mounted application. Mata, Jaramillo, and Claramunt (2011) describes an audible user-oriented interface that provides the visually impaired user with location information and orientation guidance to help the user get to the boarding gate.

Flintham et al. (2003) discusses the use of the audio channel to provide less direct contextual information to the user about the location details. Bartie and Mackaness (2006) highlight some of the key advantages and disadvantages of using a non-visual feedback system like speech-based audio. Some of the key benefits listed were - low power consumption as compared to LCD, accessible to visually impaired, secure and discreet, etc. The main disadvantages included - speech recognition errors in noisy environments, user's accent and speed of voice can affect understanding (system coaching required), does not allow user to browse the information and cannot be used by hearing impaired.

Over the last decade the field of haptics has received considerable research attention. A key conclusion drawn by several researchers (Amemiya \& Sugiyama, 2008; Erp, Veen, Jansen, \& Dobbins, 2005; Jacob et al., 2010; Lee, Cheng, Lee, Chen, \& Sandnes, 2009; Paneels \& Roberts, 2010; Pielot, Poppinga, \& Boll, 2010; Robinson et al., 2010; Williamson et al., 2010) is that in situations where it is inconvenient or less appropriate to use either visual and/or audio feedback; the sense of touch is advantageous. Costanza, Inverso, Pavlov, Allen, and Maes (2006) and Erp et al. (2005) argue that an interaction model for mobile devices should contain the following characteristics: be customisable to meet the user's requirements based on the activity the user is involved in, deliver easily understood interaction cues, and should not overly interfere with the user's current activity. In situations when vision-based or audio-based feedback for pedestrian navigation is in-appropriate we believe that haptics can provide feedback to users in the real world situations. Spatial information which is usually provided through visual channels was delivered using haptic cues by Zelek (2005). Directional information for the shortest path was provided using haptics and the information, such as street names, provided via the auditory channel.

In the next section we provide a formal overview of using haptics in a GIS context. More specifically this classification is focused on applications combining the use of haptic interaction with decision making based on spatial data and information for pedestrian navigation applications.

\section{Haptic feedback for pedestrian navigation}

Haptic feedback can be integrated for use in a wide range of GIS applications. Examples include: knowledge discovery for a tourist in a city (Robinson et al., 2009a, 2009b) and notifications for users who are using public transport (Jacob, Shalaik et al., 2011). There is potential for integration of haptics into mobile GIS. Researchers have moved from work on haptics in a virtual 
environment (Erp et al., 2005) to providing navigation assistance in a real environment (Elliott, Erp, Redden, \& Duistermaat, 2010). Using haptic feedback for pedestrian navigation for visually impaired and non-visually impaired has gained popularity amongst many researchers recently (Amemiya \& Sugiyama, 2008; Elliott et al., 2010; Erp et al., 2005; Jacob, Mooney, Corcoran, \& Winstanley, 2011; Pielot \& Boll, 2010). A haptic-interaction model from our earlier work (Jacob et al., 2010) was integrated into pedestrian navigation applications in our recent work (Jacob, Mooney et al., 2011). Klippel, Hansen, Richter, and Winter (2009) argue that turn-by-turn direction instructions are often too detailed leading to cognitive overload or unnecessarily complex. Robinson et al. demonstrated the need to move away from the turn by turn instruction to a system which gives the users the freedom to navigate according to their choice using haptic feedback for assistance (Robinson et al., 2010). Robinson et al. provides distance and orientation information to the user via vibrations with varying pattern and frequency. Asif, Heuten, and Boll (2010) extend this concept to automobile drivers. The driver perceives countable vibro-tactile pulses, which indicate the distance in turn by turn instructions. They found that the approach is a simple way of encoding complex navigational information.

Spatial strategies can be either egocentric (body-centred) or allocentric (environment-centred), and O'Keefe and Nadel (1978) have suggested that there is a dichotomy between the two (Roche et al., 2005). Learning the layout of an environment can involve strategies such as exploration and search, and in some cases the use of secondary information sources such as maps and photographs can aid the navigator in a novel or unfamiliar environment (Roche et al., 2005). Two commonly used techniques to learn the layout of the environment are either gaining route-based knowledge or survey-based knowledge. Route-based knowledge is acquired by physically navigating the environment, an egocentric strategy due to the fact that information is obtained depending on the location of the navigator (Roche et al., 2005). Route-based navigation is based on remembering specific sequences of positions that the person obtains by navigating their environment (Foo, Warren, Duchon, \& Tarr, 2005). Survey-based knowledge is incorporated and developed as a derivative of physical navigation of the environment, but the introduction of a secondary information source such as a map or photographs of the environment can lead to immediate allocentric representation for the navigator, without the need to navigate the environment (Roche et al., 2005). Studies into what is necessary to help pedestrians to navigate in pedestrian environments have discovered that landmarks are the most predominant navigation cue (May, Ross, Bayer, \& Tarkiainen, 2003). However, when landmarks are unreliable navigators appear to fall back on survey knowledge to navigate the environment (Foo et al., 2005).

In the following section we look at the haptic interaction model for pedestrian navigation system. We also discuss various haptic feedback prototypes that can be used for pedestrian navigation.

\section{Haptic interaction model for pedestrian navigation systems}

Traditionally pedestrian navigation systems have been a visual interface where the user is provided with a map interface and some extra textual information. We see that it is however impractical/inappropriate to use such visual interfaces at all time. We investigated into the integration of haptics as a modality to provide navigation cues to the user. This enables the user to switch to a non-visual feedback mechanism when the user chooses not to use a visual interface. The user can choose between the prototypes based - system complexity, the kind (frequency) of feedback, battery usage, how much (turn-by-turn vs. destination only) feedback they require, and most importantly based on their requirements/ needs. Fig. 1 illustrates a model for haptic interaction in a pedestrian navigation system. The user action along with the location, orientation and destination are sent to the server as inputs to the system. The broker service receives this information and provides instructions back to the client after processing this information. Based on the interaction type chosen by the user, they are provided with haptic feedback in the form of vibration alarm along with some simple visual cues like colour coded buttons and textual description.

There are four classifications of client applications for pedestrian navigation applications (Jacob, Mooney, \& Winstanley, 2011). Haptic StayonPath is a prototype where the user selects a destination at the start point. Haptic StayonPath does not use the compass on the mobile device and thus the phone can be held in the hand or left in the pocket. Therefore the user must use their own judgement at street intersections. This system is ideal when having to take the shortest path across an open area.

The Haptic Navigator is a waypoint-by-waypoint pedestrian navigation system using haptic feedback at critical waypoints in the path. In the Haptic Navigator system, the user is required to follow the shortest path from the initial start point until the destination based on system feedback. However, if the user wishes to be only informed about the general walking direction from a particular point towards the destination along the shortest path, then they can choose the Haptic WayPointer. The use of direction information in signage at road intersections has been used in various places over the years to give the user a sense of direction towards the user's destination. Some provide the direction information to various landmarks where as others provide distance information along with the direction to landmarks/points of interest. This helps the user re-orient and head along the direction required to reach their destination. The Haptic DestinationPointer is designed to provide the general direction towards the destination from any given point. By varying the frequency and pattern of vibrations we are able to encode the distance information into the haptic feedback while the user is pointing in the direction of the destination while scanning. Low frequency, long duration vibration pattern is used to represent user very close to the destination. The high frequency, shorter duration vibrations are used to represent the distance to destination being far away from the user.

We see in Fig. 2 that unlike the shortest path provided by typical map interfaces, the actual shortest path from any given origin to a destination may/may not include open areas. And the use of haptics in such cases as a modality can help the user navigate through these open areas where finding landmarks might not be possible. Table 1 provides a summary of the four haptic feedback prototypes for pedestrian navigation.

The HapticDestinationPointer uses haptic feedback to provide distance and direction information to the user. When the user initially selects the Destination Point, the distance (straight line) from origin (current location) to the selected destination is calculated and divided into three parts as shown in Fig. 3. The querying angle is dependent on this distance information of the user from the destination where the angle decreases to a much smaller range as the user is nearing the destination.

Let the origin (current location) of the user when they run the HapticDestinationPointer be $\mathrm{O}$. Let $\mathrm{D}$ be the straight line distance to the destination $\mathrm{S}$. The distance value is divided to form three distinct phases to the user's trip. For the walk when the distance ranges from the origin to the point $\mathrm{D} / 3$, the angular range for querying is set to $60^{\circ}$ and alerted using the vibration patter v1. The querying angular range for the second phase of the walk from distance $\mathrm{D} / 3$ to $2 \mathrm{D} / 3$ is set to $30^{\circ}$ with vibration patter v2 to provide 


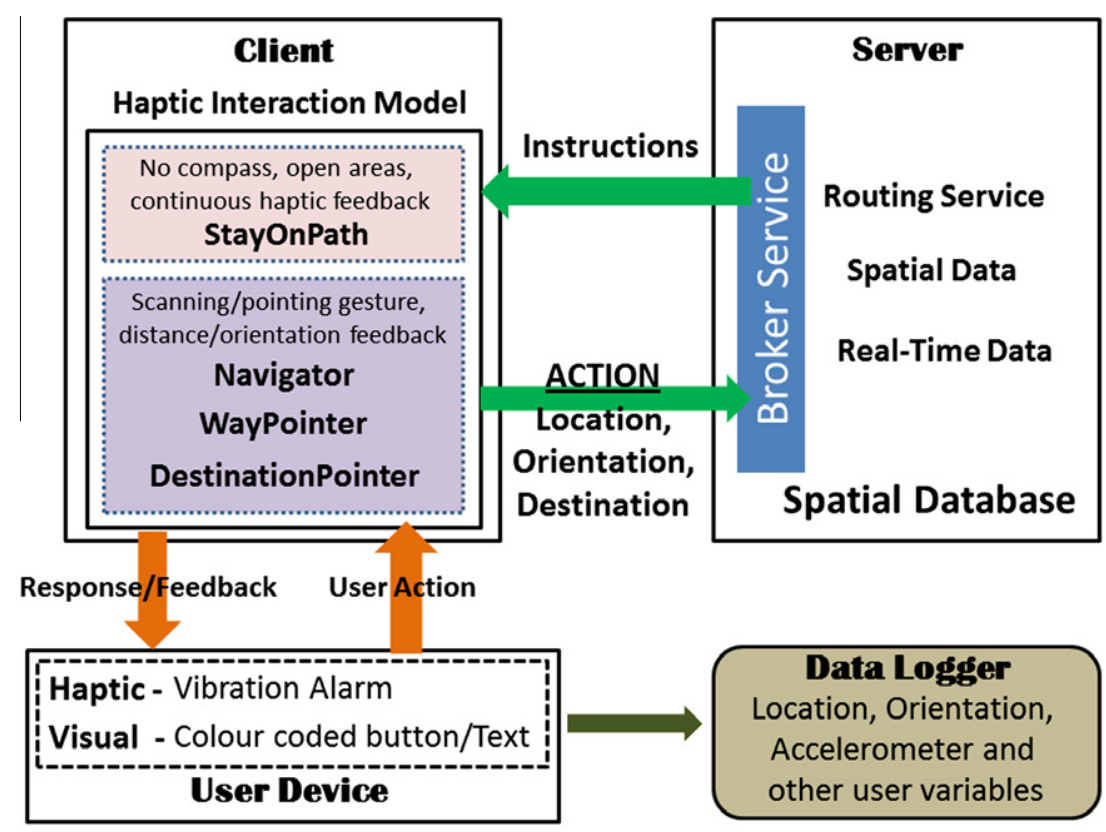

Fig. 1. Haptic interaction model for pedestrian navigation applications.
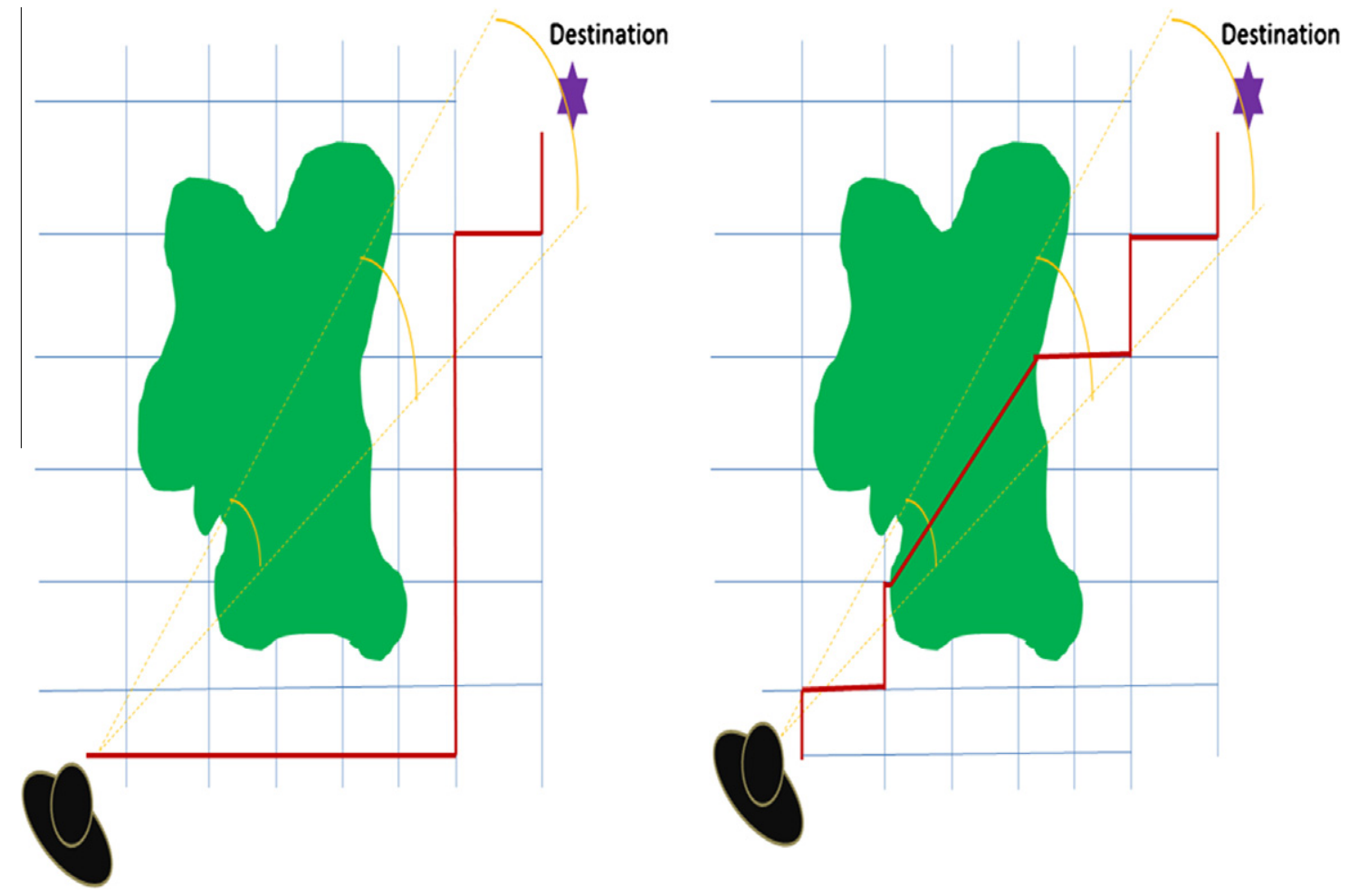

Fig. 2. Shortest path provided in a visual interface whereas the general direction of destination enables the user to walk across open areas.

feedback. During the last phase of the trip when the user is closer to the destination which is between $2 \mathrm{D} / 3$ and $\mathrm{D}$, the angular range is set to $10^{\circ}$ and the vibration patter v3 is used. The user performs the 'scan function' where they hold the mobile device parallel to the ground and move it around them slowly to be alerted of the direction they need to start walking. The user is alerted with a unique continuous vibration feedback when the user reaches within $10 \mathrm{~m}$ of the Destination Point. The bearing between the user's current location and the destination is calculated. When this bearing is equal to the compass value of the mobile device, we say that the user is pointing exactly towards the destination. With the digital compasses available on the devices, it is not ideal to fix this value to a unique angle, so we give a range within which if the user points the device, we say that the user is pointing towards the destination. So during the initial phase the range is set to be an angle that can be $\pm 30^{\circ}$ from the actual bearing between current location and destination. This angular range decreases as the user is nearing the destination.

The features and functionality of the four haptic feedback based prototypes are summarised and listed in Table 2 . 
Table 1

Summary of the four haptic feedback prototypes for pedestrian navigation.

\begin{tabular}{|c|c|c|c|c|}
\hline & StayonPath & Navigator & Waypointer & DestinationPointer \\
\hline $\begin{array}{l}\text { Haptic } \\
\text { feedback }\end{array}$ & Yes & Yes & Yes & Yes \\
\hline $\begin{array}{l}\text { Text/colour } \\
\text { code }\end{array}$ & Yes & Yes & Yes & Yes \\
\hline $\begin{array}{l}\text { Compass } \\
\text { usage }\end{array}$ & No & Yes & Yes & Yes \\
\hline $\begin{array}{l}\text { GPS 'always' } \\
\text { on }\end{array}$ & Yes & Yes & No & No \\
\hline Internet usage & High & High & Low & Low \\
\hline Battery usage & High & Medium & Low & Low \\
\hline
\end{tabular}

\section{Experiments and user trials}

Experiments were carried out to test how the user performed while using haptic feedback. Two tests were carried out to evaluate various aspects of pedestrian navigation. One was to see how effectively and successfully the user can navigate from a given origin to destination by using haptic feedback while being distracted by another person walking along and talking at all times till the completion of the task. This is to test the real-world situations that arise where the primary task is walking and/or performing some other activity and the use of assistive technologies for navigation is only a secondary task and thus diving attention between the two needs to be considered. The second test was designed to test the user's memory recall of the region after completion of navigation tasks based on landmark image based navigation and haptic feedback based navigation.

\subsection{Navigation skill test}

Research question: Can haptics be used for pedestrian navigation by a user involved in another primary task (in this case chatting with a friend) as they walk towards the destination location?

To test the haptic interaction model, we tested the Haptic DestinationPointer with 15 participants. The participants were given a 5 min talk before they do the test about the feedback patterns to help them familiarise with the feedback representing distance information. The origin and destination were fixed for all the users, but the users are not informed what the destination is. The users were given the mobile device which had the Haptic DestinationPointer application installed. They were asked to navigate to this unknown destination based on only haptic feedback they receive from the mobile device without any visual interface. The start and Destination Point along with the shortest path described by the Cloudmade (Cloudmade, 2012) routing service between the two points is shown in Fig. 8. The total distance between the origin and destination along the shortest path was $540 \mathrm{~m}$ and $390 \mathrm{~m}$ was the straight-line distance if measured as the crow flies.

When the participants walked towards the destination, another person walked along to distract the user by talking and thus provide a more real-world situation of actually exploring places when the usage of navigation assistance was the secondary activity. Hence the use of device to help navigation was the secondary task and the actual navigation with the friend being the primary task. As the user performed the test, the compass and accelerometer readings were stored to understand in detail the path taken for post navigation analysis. The compass readings along the path shows the regions where the user performed the scan operations due to confusions about the right path, the accelerometer enables us to understand the spots/regions in the path where the user paused or was standing still trying to reorient as the user was unsure.

\subsection{Memory recall test}

Research question: Can haptic feedback ensure better memory recall of the area by users after a navigation task as compared to vision based systems?

The 18 participants involved in this experiment were selected from a population of 3rd level students that were unfamiliar with the area where tests were carried out. Some participants attended NUI Maynooth while other participants attended other universities in the surrounding area of Dublin. The participants were randomly allocated to one of the three groups - the Control Group, Experimental Group 1 or Experimental Group 2. The Control Group $(n=7)$ had a mean age of $19.29(\mathrm{SD}=1.113)$, Experimental Group $1(n=6)$ had a mean age of $19.83(\mathrm{SD}=.983)$, and Experimental

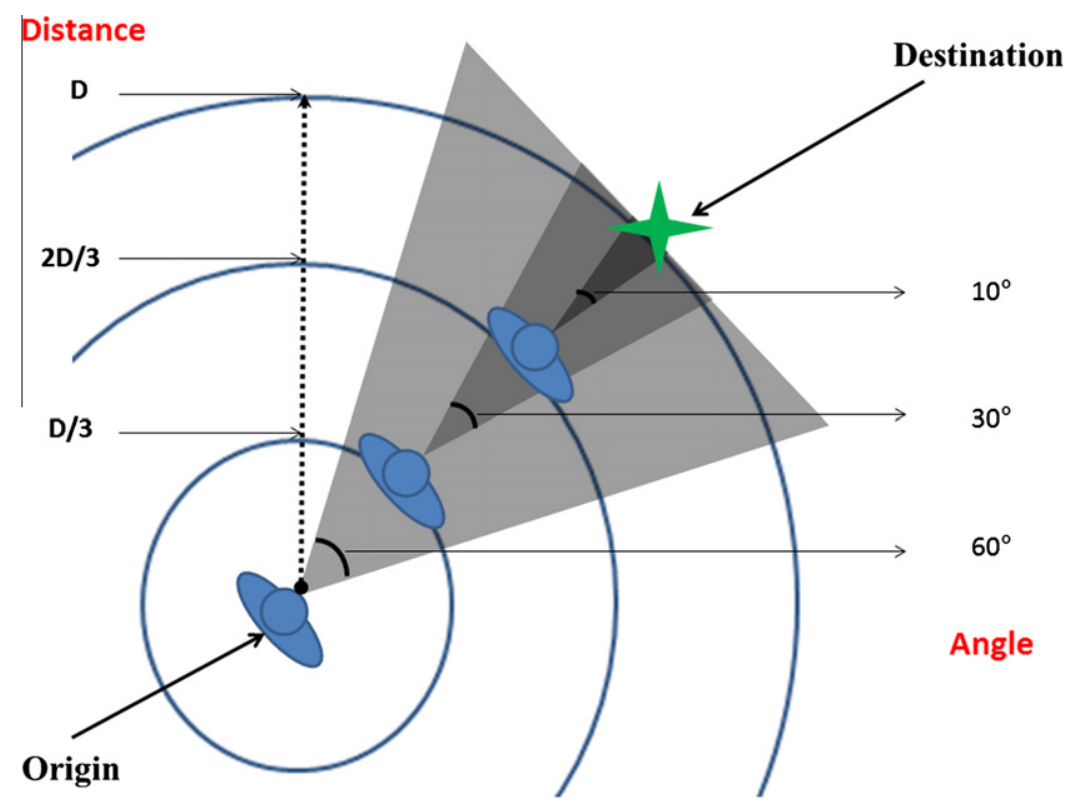

Fig. 3. Change in querying angle based on distance of user from the destination. 
Group $2(n=5)$ had a mean age of 21.60 ( $\mathrm{SD}=1.517)$. All participants gave informed consent to partake in the experiment.
Participants were required to complete a number of control tasks including the Cognitive Failures Questionnaire (Broadbent,

Table 2

Features and functionalities of pedestrian navigation prototypes using haptic feedback.

\begin{tabular}{|c|c|c|c|}
\hline StayOnPath & Navigator & WayPointer & DestinationPointer \\
\hline $\begin{array}{l}\text { No Compass } \\
\text { used }\end{array}$ & $\begin{array}{l}\text { Works using the 'waypoint-by-waypoint' } \\
\text { navigation assistance technique }\end{array}$ & $\begin{array}{l}\text { Works using the point-to-'waypoint navigation } \\
\text { assistance technique }\end{array}$ & $\begin{array}{l}\text { Works using the point-to-destination' } \\
\text { navigation assistance technique }\end{array}$ \\
\hline $\begin{array}{l}\text { Works using } \\
\text { the Hot/ } \\
\text { Cold' } \\
\text { technique }\end{array}$ & & & \\
\hline $\begin{array}{l}\text { Phone can be } \\
\text { held in the } \\
\text { hand or left } \\
\text { in the } \\
\text { pocket }\end{array}$ & $\begin{array}{l}\text { Provides waypoint-by-waypoint assistance } \\
\text { when getting from one place to the other in an } \\
\text { unfamiliar city/town }\end{array}$ & $\begin{array}{l}\text { Provides assistance when expecting initial general } \\
\text { heading information along the shortest route }\end{array}$ & $\begin{array}{l}\text { Provides assistance when expecting general } \\
\text { heading information towards destination }\end{array}$ \\
\hline $\begin{array}{l}\text { Good for } \\
\text { walking } \\
\text { across open } \\
\text { areas }\end{array}$ & $\begin{array}{l}\text { Phone should be held In the hand for } \\
\text { performing the scanning operation }\end{array}$ & $\begin{array}{l}\text { Phone should be held in the hand for performing } \\
\text { the scanning operation when at points along the } \\
\text { trip the users wish to reassure themselves of the } \\
\text { shortest path from current location }\end{array}$ & $\begin{array}{l}\text { Phone should be held in the hand for } \\
\text { performing the scanning operation when at } \\
\text { points along the trip the users wish to } \\
\text { reassure themselves of the direction towards } \\
\text { destination }\end{array}$ \\
\hline \multirow[t]{2}{*}{$\begin{array}{l}\text { Continuous } \\
\text { feedback as } \\
\text { you walk } \\
\text { along a path }\end{array}$} & $\begin{array}{l}\text { Does not require user attention while walking } \\
\text { towards the next waypoint as they will be } \\
\text { alerted when they need to make a change in } \\
\text { their walking direction } \\
\text { Feedback only when pointing in the direction } \\
\text { of the next waypoint or about arrival at a new } \\
\text { waypoint }\end{array}$ & $\begin{array}{l}\text { Does not require user attention while walking as } \\
\text { they are In 'explore mode' and so will only need to } \\
\text { query when in doubt }\end{array}$ & $\begin{array}{l}\text { Does not require user attention while walking } \\
\text { as they are in explore mode' and so will only } \\
\text { need to query when in doubt }\end{array}$ \\
\hline & & $\begin{array}{l}\text { Feedback only when pointing in the direction of } \\
\text { the next waypoint from any point in the path }\end{array}$ & $\begin{array}{l}\text { Ensures faster walking speed in the general } \\
\text { direction of destination } \\
\text { Feedback only when pointing in the direction } \\
\text { of the destination from any point in the path }\end{array}$ \\
\hline
\end{tabular}

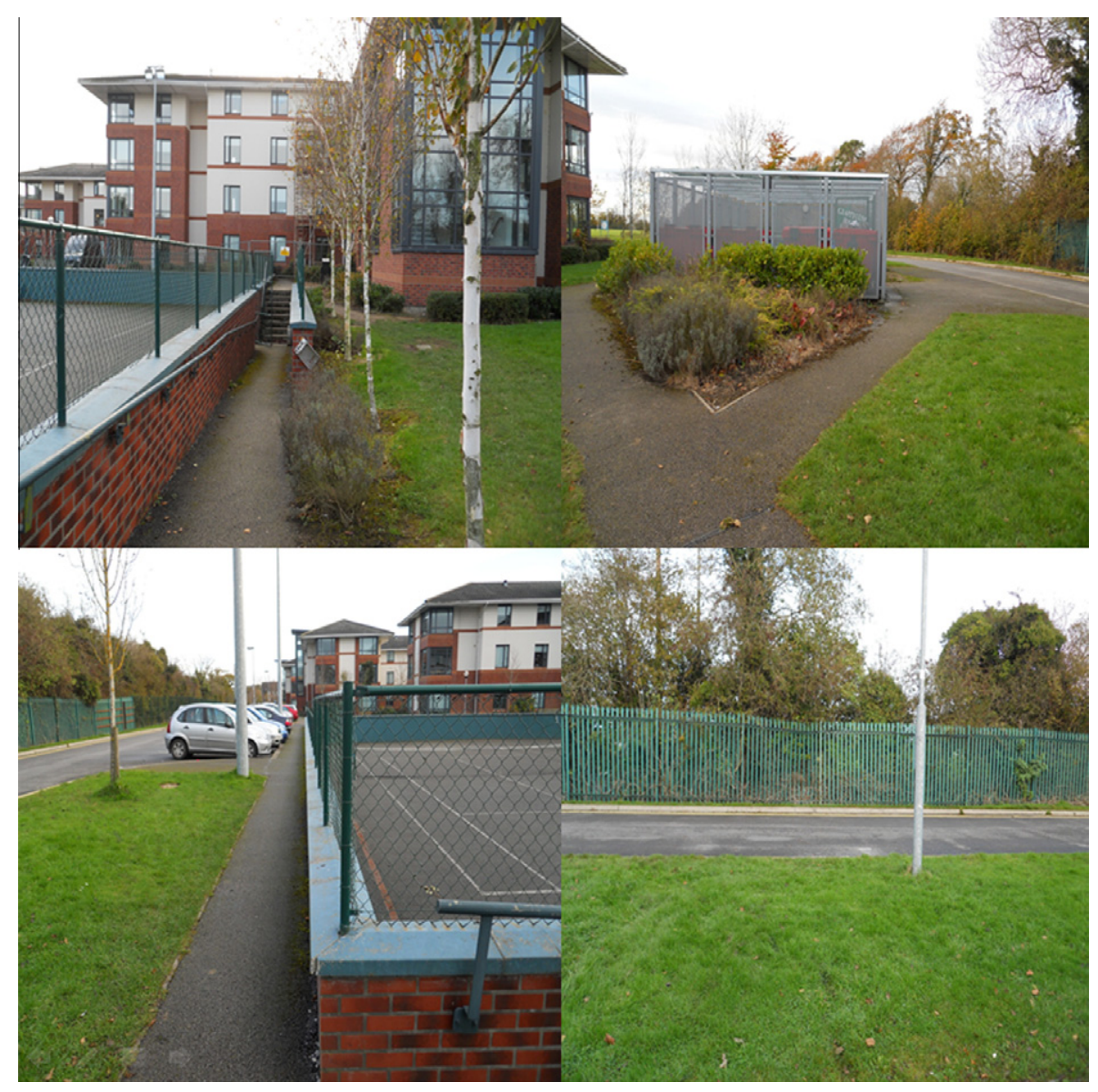

Fig. 4. Panoramic images of the Destination Point that were shown to the Control Group and the Experimental Group 2. 
Cooper, Fitzgerald, \& Parkes, 1982), the National Adult Reading Test (Nelson, 1982), the Trail Making Test (Reitan, 1955) and a Mental Rotations task (Shepard \& Cooper).

The Trail Making Test (TMT) was presented to participants in a pen and paper format. The TMT provides information on attributes such as visual processing, visual search and executive function (Reitan, 1958). The National Adult Reading Test (NART) consisted of 50 single words of varying difficulty that were presented as a word list on a single sheet of paper. The NART is used as a prediction of IQ and general intelligence (Nelson, 1982). The number of words that the participant pronounced correctly translated into a score of Full-Scale IQ, Verbal IQ and Performance IQ. The Mental Rotations Task was presented to the participants in a pen and paper format. The Mental Rotations Task is used as a method of assessing participant's spatial rotation abilities (Shepard \& Metzler, 1971).

The Control Group and the Experimental Group 2 were shown four photographs of the Destination Point at the start of the experiment in order to locate it as shown in Fig. 4. The Experimental Group 2 was shown a series of six photographs at Starting Point $A$ and at Starting Point B which illustrated the route that they should take to the Destination Point. The Experimental Group 1 used haptic feedback to help navigate to the Destination Point using the HapticDestinationPointer system as shown in Fig. 3. Participants were timed while navigating from Starting Point A to the Destination Point and from Starting Point B to the Destination Point using a stop watch device on a mobile phone. At the completion of the experiment participants were instructed to draw a map of the area of the area they were at on an A4 sized paper that already included the outline of the road surrounding the apartment complete. A map key was used to score the maps, which were given a mark out of 25 for each participant. Marks were given for including the Destination Point, Starting Point A and Starting Point $\mathrm{B}$, as well as marks for including buildings, the Tennis Courts and the bins located beside the Destination Point. Participants were not restricted to drawing buildings and were told to include any information that they could recall. Participants were not told before completion of the test about having to prepare a map as we did not want the participants to intentionally try and remember features for the post navigation task.

\section{Results and discussions}

In this section we discuss the finding and results in detail of the two tests that have been carried out for navigation and memory recall.

\subsection{Navigation test}

All the 15 participants completed the tests successfully as they all reached the destination. Table 3 provides a summary of the 15 users who took the user trials. Almost all the users walked over open areas and paved walkways to reach their destination. The average time of completion by all participants was $865 \mathrm{~s}$ while the average distance travelled to reach destination was found to be $807 \mathrm{~m}$. The time of $540 \mathrm{~s}$ to reach the destination by 'user 2' was the fastest recorded time while the 'user 3' took the longest time (1192 s) to complete the task. The shortest travel distance was also recorded by 'user 2' (652.57 $\mathrm{m})$ where the longest travel distance of $949.89 \mathrm{~m}$ was recorded by 'user 7'.

According to the Cloudmade routing service, the time required to traverse the shortest path to the destination was $390 \mathrm{~s}$ (thus walking at a speed of $1.38 \mathrm{~m} / \mathrm{s}$ ) which seems very unlikely in a real world situation. The average walking speed recorded for the user trials was $0.93 \mathrm{~m} / \mathrm{s}$. Some users walked very fast while
Table 3

Summary of the user trials.

\begin{tabular}{|c|c|c|c|}
\hline User & $\begin{array}{l}\text { Distance } \\
\text { Travelled } \\
(\text { in } \mathrm{m})\end{array}$ & $\begin{array}{l}\text { Time Taken } \\
\text { (in s) }\end{array}$ & Comments \\
\hline 1 & 856.16 & 1160 & Walked across grass and car parks \\
\hline 2 & 652.57 & 540 & Finished task in the quickest time \\
\hline 3 & 938.84 & 1192 & Took the longest time to finish the task \\
\hline 4 & 812.68 & 960 & Was taking more time at certain points \\
\hline 5 & 784.32 & 790 & $\begin{array}{l}\text { Felt feedbacks were easy to } \\
\text { understand }\end{array}$ \\
\hline 6 & 845.12 & 878 & Walked fast across open areas \\
\hline 7 & 949.89 & 940 & $\begin{array}{l}\text { Walked the longest distance. Poor with } \\
\text { orientation }\end{array}$ \\
\hline 8 & 758.22 & 748 & Took time to re-orient at certain points \\
\hline 9 & 833.86 & 850 & $\begin{array}{l}\text { Used mostly paved ways. Paused more } \\
\text { often }\end{array}$ \\
\hline 10 & 912.31 & 975 & $\begin{array}{l}\text { Was finding it difficult to re-orient } \\
\text { near the buildings }\end{array}$ \\
\hline 11 & 885.43 & 914 & Walked across grass/car parks \\
\hline 12 & 781.32 & 843 & Felt feedback was very subtle and good \\
\hline 13 & 692.54 & 689 & $\begin{array}{l}\text { Walked across cark parks and beside } \\
\text { buildings }\end{array}$ \\
\hline 14 & 688.76 & 735 & Took the path between the buildings \\
\hline 15 & 711.87 & 759 & Walked across open grass fields \\
\hline
\end{tabular}

performing the trials while others chose to walk slowly and check the general walking direction when at certain critical points in the path. The users commented on how subtle the feedback was' and the about not having to continuously interact with the device. During the user trials, they could get to the destination without taking their attention off their conversation with a friend while walking towards the destination. This benefit of not having to continuously look into the mobile screen for navigation assistance was cited as a huge positive feature by most users. The time taken to cover that distance as per Cloudmade routing service expects the user to be walking at speeds which is relatively fast when walking along streets casually. The time taken to get to destination is significantly higher as the users were not asked to get there in the fastest possible time and thus users walked in their own pace.

Fig. 5 shows the path taken by the user who reached the destination in the shortest time. The comparison with 2 other users shows the distinct paths taken to the destination. Unlike the typical shortest path, the users walked over open areas like fields, sports pitches, car parking and also took paved walkways when necessary.

\subsection{Memory recall test}

The findings from the second test is described below for both the control task and the map drawing with also discussions about navigation time and overall performance in the post navigation task of map creation.

\subsubsection{Control tasks}

Due to an overall low number of participants and unequal participant numbers in each of the groups, non-parametric tests were used in each of the control tasks.

Results from the CFQ showed an overall mean score of 46.67 $(\mathrm{SE}=3.71)$. An independent samples Kruskal Wallis test also demonstrated that there was no significant differences between the groups on CFQ scores $(P=.095)$. Results from the Mental Rotations Task demonstrate that participants had an overall mean score of $26.61(\mathrm{SE}=1.58)$. An independent samples Kruskal Wallis test measuring any difference between the groups revealed a significance level of .51, which almost approached significance. Further investigation of the means and SEs for each of the groups on the 


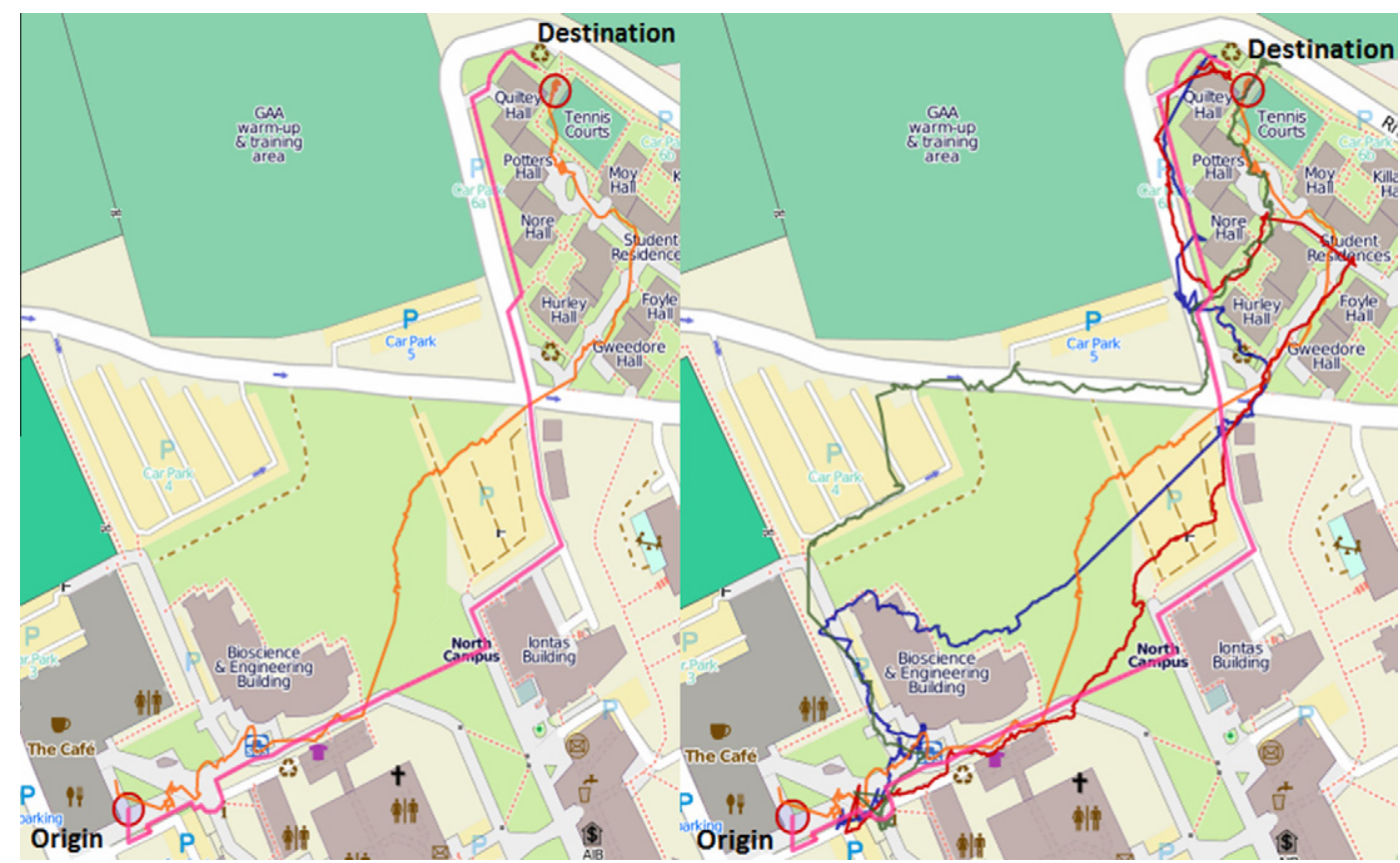

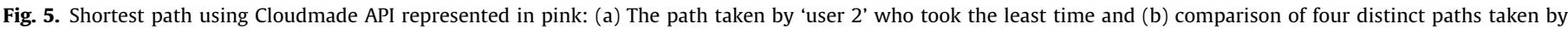
different users from origin to destination.

Table 4

Mean Scores and Standard Error Scores for the Control Group, Experimental Group 1 and Experimental Group 2.

\begin{tabular}{|c|c|c|c|c|c|c|c|c|}
\hline & CFQ & TMTA & TMTB & TMTB-A & fsIQ & pIQ & vIQ & Rotation \\
\hline Control Mean & 46.29 & 28.14 & 50.71 & 22.57 & 115.71 & 113.71 & 114.71 & 23.14 \\
\hline Control SE & 8.017 & 5.701 & 8.283 & 3.651 & 1.643 & 1.443 & 1.443 & 2.558 \\
\hline Exp 1 Mean & 54.83 & 25.00 & 51.17 & 26.17 & 111.50 & 109.67 & 110.67 & 25.33 \\
\hline Exp $1 \mathrm{SE}$ & 3.628 & 2.543 & 5.700 & 3.919 & 1.500 & 1.382 & 1.382 & 2.431 \\
\hline Exp 2 Mean & 37.40 & 20.80 & 38.00 & 17.20 & 116.80 & 114.40 & 115.50 & 33.00 \\
\hline Exp 2 SE & 3.816 & 3.652 & 1.378 & 3.499 & 1.715 & 1.536 & 1.536 & .894 \\
\hline
\end{tabular}

Rotations task (see Table 4 ) revealed that the greatest difference was between the Control Group $(M=23.14, \mathrm{SE}=2.558)$ and the Experimental Group $2(M=33.00, \mathrm{SE}=.894)$.

Results conducted on the Trail Making Test revealed an overall mean score for TMTA as 25.06 ( $\mathrm{SE}=2.55$ ), an overall mean score for TMTB as 47.33 ( $\mathrm{SE}=3.83$ ) and an overall mean score for TMTB-A as 22.28 ( $\mathrm{SE}=2.203$ ). An independent sample Kruskal Wallis test revealed that there was no significant difference found between the Control Group, Experimental Group 1 or Experimental Group 2 on either TMTA scores $(p=.365)$, TMTB scores $(p=.342)$ or the scores on TMTB-A $(p=.194)$.

Results conducted on the NART revealed an overall mean score for full scale IQ as 114.16 ( $\mathrm{SE}=1.04$ ), an overall mean score for performance IQ as 112.56 ( $\mathrm{SE}=.94$ ), and an overall mean score for verbal IQ as $113.56(\mathrm{SE}=.94)$. An independent sample Kruskal Wallis test also revealed no significant differences between the groups on full scale IQ ( $p=.079)$, performance IQ $(p=.079)$ or verbal IQ $(p=.079)$. Results from the Control Tasks demonstrated that all of the participants had normal cognitive functioning and there were no significant differences found between the Control group, Experimental Group 1 or Experimental Group 2 on any of the tasks.

Table 4 shows the Mean Scores and Standard Error Scores for the Control Group, Experimental Group 1 and Experimental Group 2 on the Cognitive Failures Questionnaire (CFQ), the Trail Making Test Part A (TMTA), the Trail Making Test Part B (TMTB), the difference between them (TMTB-A), the NART scores - Full Scale IQ (fsIQ), Performance IQ (pIQ) and Verbal IQ (vIQ) and the Mental Rotations Task (Rotation).

\subsubsection{Map drawing}

A one-way between groups ANOVA was conducted to examine the difference in map drawing scores for each of the three groups. There was a main effect of group with the result almost reaching significance $F(2,15)=3.1, p=.075$. Despite not reaching statistical significance post hoc Tukey tests demonstrated that the Control Group differed from Experimental Group 1 at $p=.078$. An examination of the mean statistics revealed that the Control Group demonstrated a mean score of $9.43(\mathrm{SD}=2.82)$, Experimental Group 1 demonstrated a mean score of $13.33(\mathrm{SD}=4.03)$, while Experimental Group 2 showed a mean map score of $10.00(\mathrm{SD}=1.00)$ (see Fig. 6c).

\subsubsection{Navigation times}

A $2 \times 3$ (Navigation Time A, Navigation Time B) $\times$ (Control Group, Experimental Group 1 and Experimental Group 2) between groups multivariate ANOVA was conducted to investigate the difference in the times taken by each group to navigate from Starting Point A to the Destination Point and from Starting Point B to the Destination Point. Preliminary assumption testing was conducted to check for normality, linearity, homogeneity of variance and multicollinearity, with no serious violations noted. There was a statistically significant main effect of group at Time $\mathrm{A}-(F(2,14)=5.28$, $p=.00)$. There was also a main effect of group at Time B $(F(2,15)=3.446, p=.059)$, which almost reached significance.

A one way ANOVA was conducted to investigate the statistically significant difference found between the groups at Time A. The results demonstrated that there was a significant main effect of group $(F(2,15)=2.68, p=.00)$. Post-hoc Tukey tests revealed that 

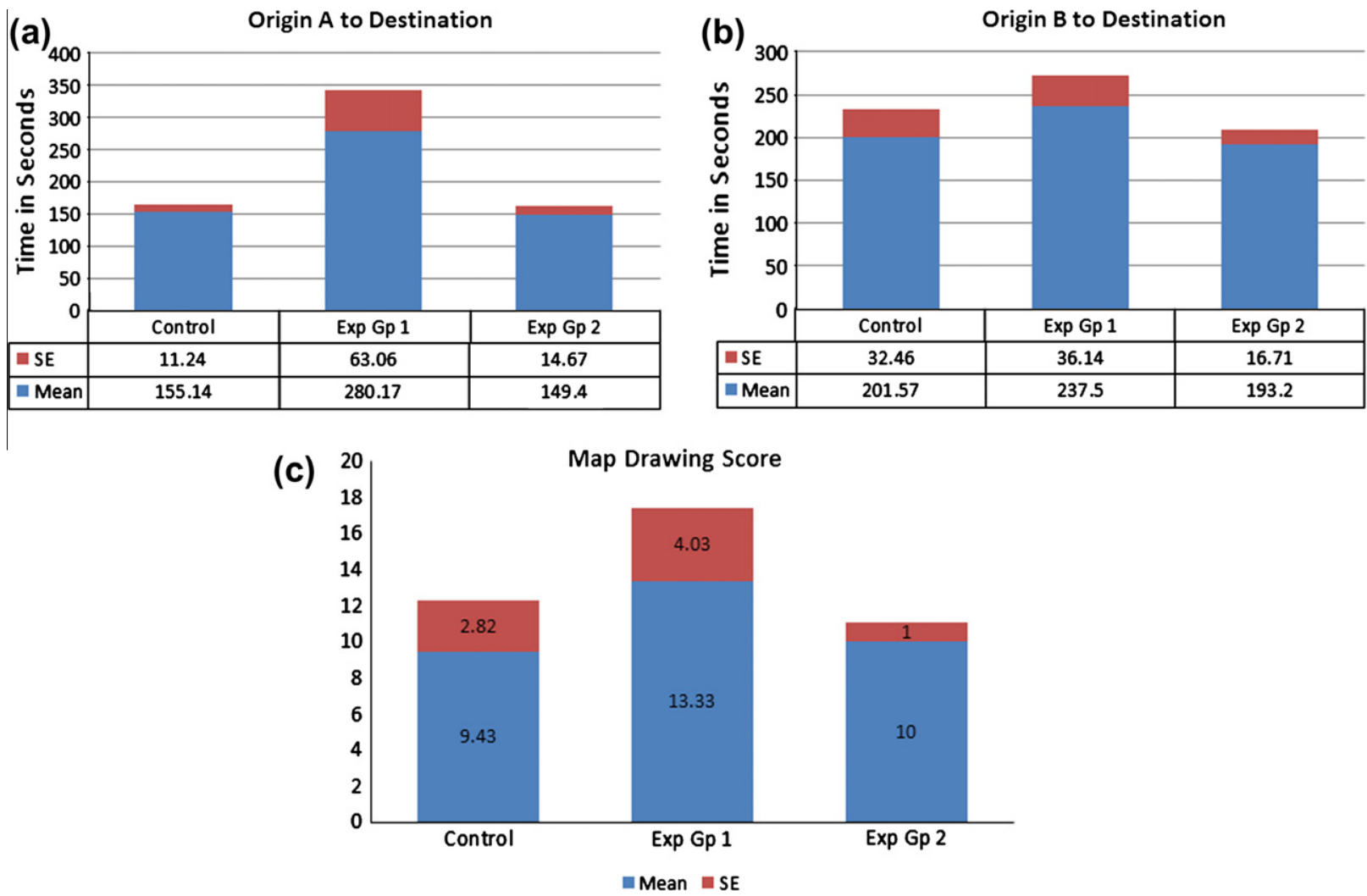

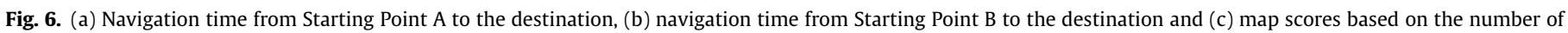
features recalled.

Experimental Group 1 differed from the Control Group at $p=.00$ and differed from Experimental Group 2 at $p=.00$. An examination of the mean statistics showed that Experimental Group 1 scored a mean time of $280.17 \mathrm{~s}(\mathrm{SD}=63.06)$, the Control Group had a mean score of $155.14 \mathrm{~s}(\mathrm{SD}=11.24)$, while Experimental Group 2 demonstrated a mean score of $149.4 \mathrm{~s}(\mathrm{SD}=14.67)$ (see Fig. 6a and b).

A one way ANOVA was then conducted to investigate the almost statistically significant difference found between the groups at Time B. The results revealed demonstrated that there was a significant main effect of group $(F(2,15)=3.446, p=.059)$. Post-hoc Tukey tests demonstrated that Experimental Group 1 and Experimental Group 2 differed from each other at $p=.073$. An examination of the mean statistics revealed that Experimental Group 1 scored a mean time of $237.5 \mathrm{~s}(\mathrm{SD}=36.14)$, Experimental Group 2 demonstrated a mean score of $193.2 \mathrm{~s}(\mathrm{SD}=16.71)$ and the Control Group scored a mean time of $201.57 \mathrm{~s}(\mathrm{SD}=32.46)$.

\subsubsection{Routes}

Six key routes taken by the participants were identified Routes 1, 2 and 3 from Starting Point A to the Destination Point and Routes 4, 5 and 6 from Starting Point B to the Destination Point (see Fig. 7).

Experimental Group 2 were shown photographs of Route 2 from Starting Point A and photographs of Route 5 from Starting Point B. Analysing the routes taken by each participant showed that the majority (57.1\%) of the Control Group followed Route 1 from Starting Point $\mathrm{A}$, while the majority (66.7\%) of Experimental Group 1 followed Route 3 from Starting Point A, with 100\% of Experimental Group 2 following Route 2 (see Fig. 8a). Analysing the routes taken by each participant from Starting Point B to the Destination Point revealed that the majority of both the Control Group (71.4\%) and Experimental Group 1 (83.3\%) followed Route 5, while $100 \%$ of
Experimental Group 2 followed Route 2 also (see Fig. 8b). Overall the most popular route from Starting Point A was Route 2, with Route 1 being the least popular, and the most popular route from Starting Point B was Route 5, with Route 4 being the least popular.

To summarise, the results indicated that the participants using the haptic technology took a significantly longer time to reach the Destination Point when navigating from Starting Point A and also took a longer time to reach the Destination Point when navigation from Starting Point B when compared to Experimental Group 2, with the result almost reaching statistical significance. However Experimental Group 1 also demonstrated higher map scores in comparison to the Control Group, who were told to navigate the environment freely, and the Experimental Group 2, who used route based photographs as a guide to navigation, with this difference almost approaching statistical significance.

\subsection{Discussion}

Based on the findings from the navigation tasks using HapticDestinationPointer, it is seen that the users were able to successfully reach the destination without any visual feedback and perform the task even though they were being distracted by another user while the navigation task is to be performed.

Principle findings from the memory recall experiment indicate that those in Experimental Group 1 using the haptic feedback to help navigate the environment took significantly longer than those in the Control Group or Experimental Group 2 who were using the route based photographs as a guide. Experimental Group 1 took significantly longer when navigating from Starting Point $A$ to the Destination Point and also took longer when navigating from Starting Point $\mathrm{B}$ to the Destination Point, with the result almost approaching significance. There was also an almost significant ef- 


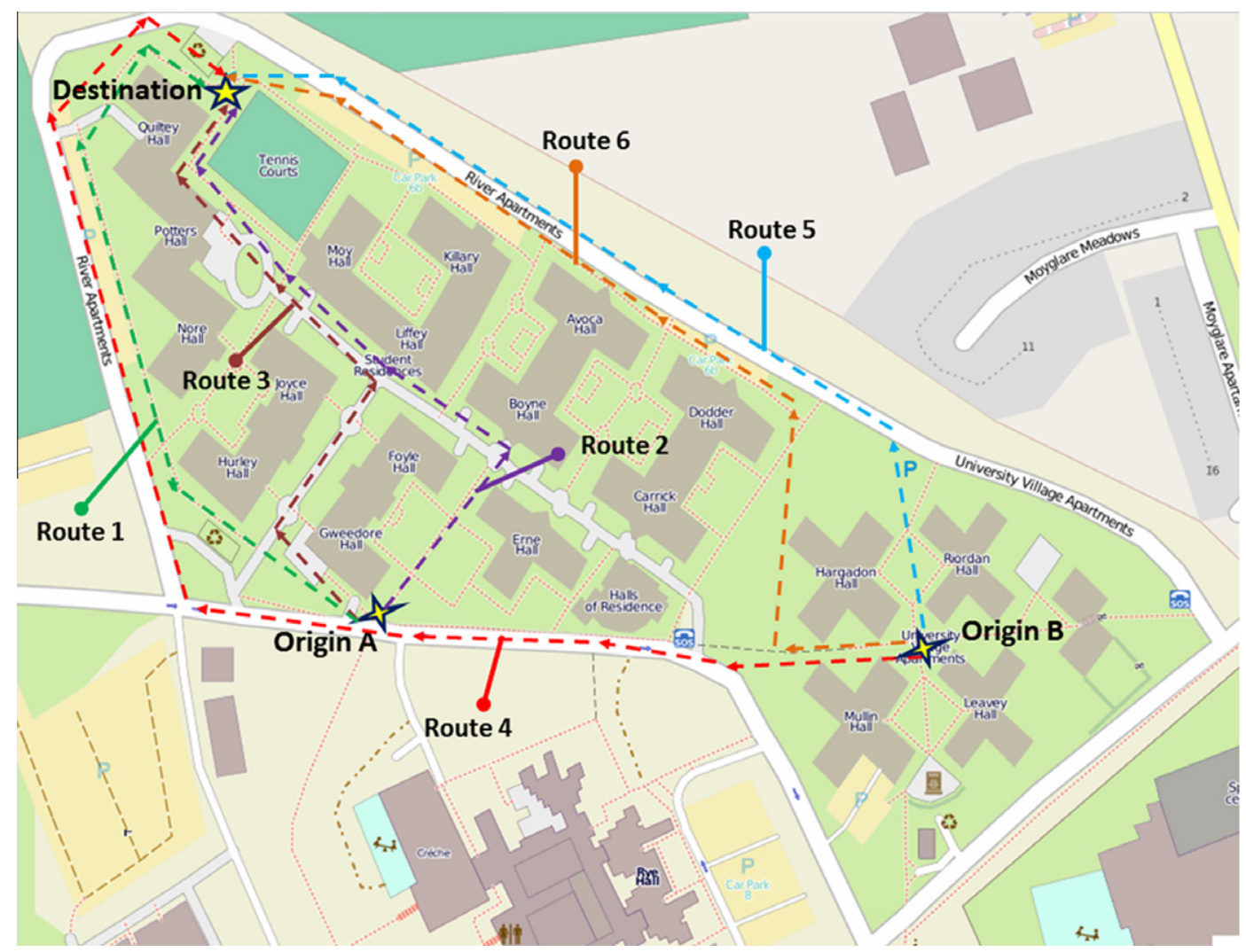

Fig. 7. Map of the six routes identified, as well as Starting Point A, Starting Point B and the Destination Point.

(a)

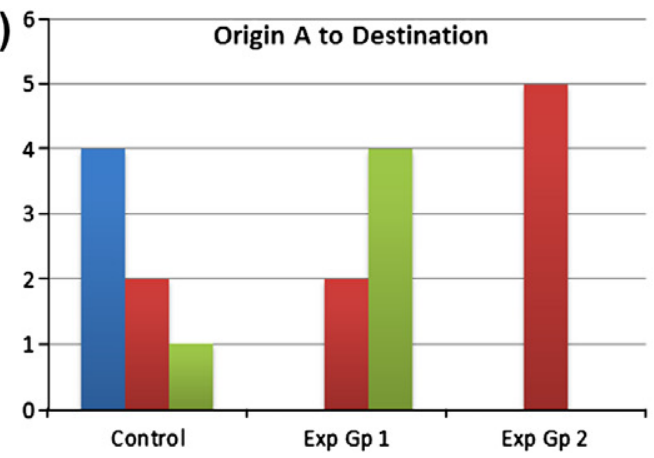

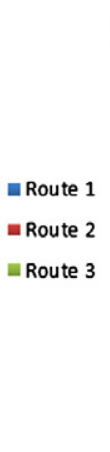

(b)

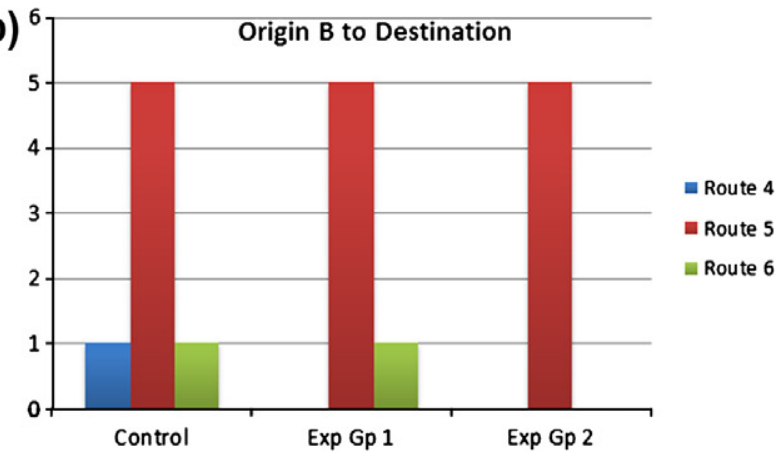

Fig. 8. (a) The routes taken from origin A to destination (b) The routes taken from origin B to destination.

fect discovered when examining the map scores of the participants across the three groups - those who were aided by haptic technology when locating the Destination Point had better maps overall, compared to the Control Group and Experimental Group 2. An example of a map created by the user based on memory recall is shown in Fig. 9 with comparison to the same region on OpenStreetMap.

The significant result obtained when comparing the times taken could be explained as follows. As the Control Group and Experimental Group 2 both were shown four photographs of the Destination Point so they knew what key landmarks to look out for and to alert them that they had reached their location. Experimental Group 1 who were not given any visual cues were relying strictly on haptic feedback did not have this to depend on, and only knew they had reached the location when the mobile phone started to vibrate continuously. It has been demonstrated in previous research that participants can reach an unknown location in an unfamiliar environment assisted only by haptic feedback (Robinson et al.,
2010). However the Control Group and Experimental Group 2 could be at an advantage as they could notice the landmarks of the Destination Point from a distance and therefore navigate towards it. This could explain why those in Experimental Group 1 spent a longer time locating the Destination Point from Starting Point A.

Experimental Group 1 also took a longer time locating the Destination Point from Starting Point B, with the result almost reaching significance. This could possibly be explained by the fact that participants would be unfamiliar with the method of scanning that was used to give haptic feedback to the participant when the device was pointed in the direction of the Destination Point. It is possible that participants could have scanned too fast to pick up a vibration so this would slow the participant down when looking for feedback. It would perhaps be beneficial then to include a longer tutorial on how to accurately scan and search for feedback before commencing the search for the Destination Point and timing the participant. Scanning also has another disadvantage as it is 


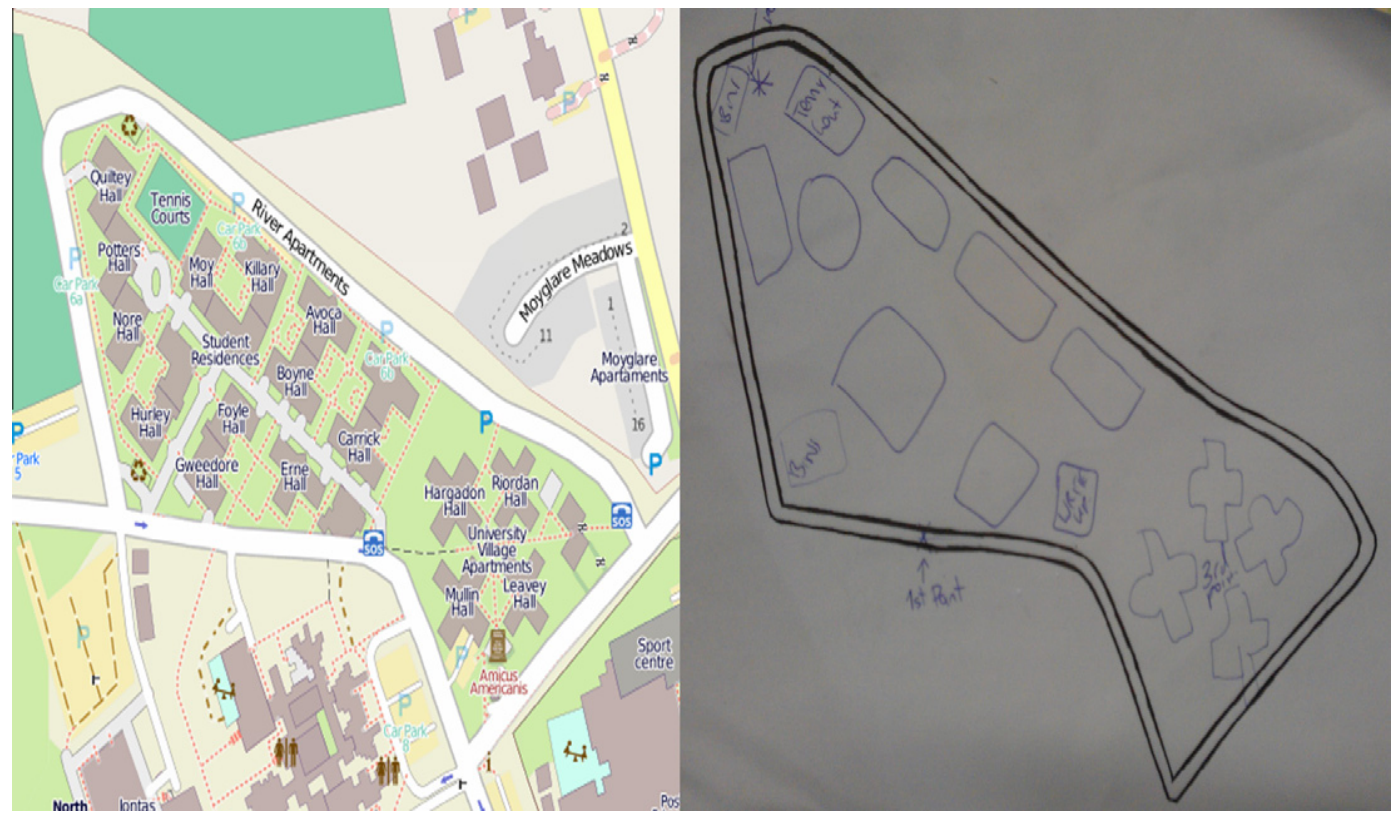

Fig. 9. An example of the map drawn post navigation task for the memory recall test.

more obtrusive and obvious that someone is trying to navigate their environment (Pielot et al., 2010). Although scanning was the technique that was used for this experiment it is also possible to have the device placed in your jacket pocket, then pointing and scanning for feedback to ensure user privacy (Jacob, Mooney et al., 2011). The user will also be safe in the knowledge that they do not seem like a tourist or stranger to the area, which is an issue for most navigators (Robinson et al., 2010).

The almost significant result obtained from the map scores which illustrated that those in Experimental Group 1 scored higher maps in comparison to the other two groups can also be explained in reference to the photographs shown at the start. As was already stated the Control Group and Experimental Group 2 had prior knowledge of what the Destination Point looked like via photographs. Experimental Group 1 had no knowledge of what the Destination Point looked like when they began the experiment, therefore it may be possible that this had an effect on recall. Previous work has also indicated that use of tactile displays used to assist navigation can improve the attention of the user (Pielot et al., 2010). Studies have indicated that participants who use a tactile display while navigating pay more attention to the immediate surroundings of their environment (Pielot et al., 2010). As well as this, in experiments where the participant was asked to actively search for landmarks and other items while navigating the environment it was demonstrated that those using tactile displays are able to locate and notice more items (Elliott et al., 2010). Pielot also noted a positive tendency in their study for those in the tactile condition to notice more entities (benches) than those in the visual condition. This could be a possible reason for the higher map scores of Experimental Group 1.

All participants in Experimental Group 2 followed the routes they were shown on the photos at both Starting Point A and Starting Point $B$ to reach the Destination Point. These were Route 2 from Starting Point A and Route 5 from Starting Point B as shown in Fig. 7. Experimental Group 1 followed mainly similar routes to Experimental Group 2, especially when navigating from Starting Point B to the Destination Point. It is interesting to note that nearly all participants in the Control Group navigated left (Route 1) when instructed to navigate freely. This can be explained by the fact that in the four photographs of the Destination Point, the site of the general rubbish and recycling bins was clearly visible and participants may have been attracted to the bins situated to the left of Starting Point A, thinking that they could possibly be the bins in the photograph of the destination. The examination of the routes taken by the participants provided another possible reason of why Experimental Group 1 had higher map drawing scores, with the result approaching significance. The majority of participants in the Control Group took an alternative Route (Route 1) that did not bring them into the central part of the apartment. None of the participants in Experimental Group 1 or Experimental Group 2 followed this route to reach the Destination Point, instead choosing Routes that took them into a more central part of the campus accommodation area where they were navigating. This could have made a difference to the map drawing scores as it is possible that these Groups were exposed to more landmarks than the Control Group and were therefore able to recall and draw more landmarks like buildings, and bins on the map.

\section{Conclusions and future work}

When the users use mobile-based navigation systems they are usually in an outdoor environment and not within the protected environment of a car, bus, or train. As outlined in this paper there are situations where interaction with the visual display on a mobile device is inappropriate or unsuitable. We have seen here that the users were able to successfully navigate and reach their destinations without the aid of a visual interface like a map. With the experiments we were able to see in this paper that memory recall of the environment post tests are best while using haptic feedback as the mode for navigation. Thus the usefulness of haptic feedback in pedestrian navigation systems can be highlighted. Our paper outlines taxonomy of approaches to integrating haptics into mobile-based navigation systems for pedestrian navigation. As smartphones continue their technological evolution, more sensors will be integrated into the mobile hardware such as noise sensors (Estrin, 2010) or air quality sensors (Whitney \& Richter Lipford, 2011). As the results from the study carried out by Heikkinen, Olsson, and Vanen-Vainio-Mattila (2009) concludes users seen haptic-feedback 
as a compliment to the existing modalities rather than it being a stand-alone modality.

We feel that when integrating tactile with visual feedback environmental awareness should be supported through the visual modality and local guidance through the tactile channel, as concluded by Elliott et al. (2010). Their result confirmed that a haptic-based system is viable and can operate effectively in extremely demanding situations. Some authors such as Parush et al. have found that, in general, there is degradation of spatial knowledge amongst the general public caused by the extensive use and reliance upon automated systems for navigation and spatial data discovery (Parush, Ahuvia, \& Erev, 2007). This is an issue for concern. However, we believe that haptics offers many benefits as a key modality for integration into mobile-based GIS applications. Amemiya et al. illustrates how haptic feedback can be effectively used to help visually impaired individuals navigate in an indoor environment (Amemiya et al., 2008). Jacob et al. (2010) described how using haptic feedback via varying vibration alarm patterns in a mobile device can be used to help visually impaired users without burdening them with having to carry extra hardware or devices. While the benefits for visually impaired is one of the feature of haptics, it can be of similar use to users who want low interaction, non-intrusive feedback. Vibrotactile cues can be used as a channel which provides 'private information' in an easy to understand manner for the user (Li, Sohn, Huang, \& Griswold, 2008). While the granularity of detail that can be represented using such systems is limited, it can be efficiently used to convey a certain notification message in a high level form. Haptics can provide the opportunities for the user to interact more with the real-world environment around them and rely less on visual interaction with the mobile device. From the results of the user-trials carried out we see potential use of haptics as a modality to communicate with mobile location based services to provide information in a subtle, easy to understand manner without distracting the user. We understand that the tests that are carried out here are not exhaustive. More extensive user trials need to be carried out to determine the use of haptics in a real-world urban scenario for navigation.

\section{Acknowledgements}

Research presented in this paper was funded by a Strategic Research Cluster Grant (07/SRC/I1168) by Science Foundation Ireland under the National Development Plan. We thank all the students who took part in the user trials. We acknowledge the inputs from our colleagues at the Department of Psychology. The authors gratefully acknowledge this support.

\section{References}

Amemiya, T., Ando, H., \& Ando, T. (2008). Lead-me interface for a pulling sensation from hand-held devices. ACM Transactions on Applied Perception, 5(15), 1-15. 17, September 2008.

Amemiya, T., \& Sugiyama, H. (2008). Design of a haptic direction indicator for visually impaired people in emergency situations. In K. Miesenberger, J. Klaus, W. Zagler, \& A. Karshmer (Eds.). Computers helping people with special needs: Lecture notes in computer science (Vol. 5105, pp. 1141-1144). Berlin/Heidelberg: Springer.

Asif, A., Heuten, W., \& Boll, S. (2010). Exploring distance encodings with a tactile display to convey turn by turn information in automobiles. In Proceedings of the 6th Nordic conference on human-computer interaction: Extending boundaries ( $\mathrm{pp}$. 32-41). NordiCHI '10. New York, NY, USA: ACM.

Bartie, P. J., \& Mackaness, W. A. (2006). Development of a speech-based augmented reality system to support exploration of cityscape. Transactions in GIS, 10(1), 63-86.

Broadbent, D. E., Cooper, P. F., Fitzgerald, P., \& Parkes, K. R. (1982). The Cognitive Failures Questionnaire (CFQ) and its correlate. British Journal of Clinical Psychology, 21, 1-16.

Cloudmade (2012). <http://developers.cloudmade.com/projects/show/routinghttp-api> Accessed March, 2012.

Costanza, E., Inverso, S. A., Pavlov, E., Allen, R, \& Maes, P. (2006). eye-q: Eyeglass peripheral display for subtle intimate notifications. In Proceedings of the 8 th conference on Human-computer interaction with mobile devices and services (pp. 211-218). MobileHCI '06, New York, NY, USA, April: ACM.

Elliott, L., Erp, J. V., Redden, E., \& Duistermaat, M. (2010). Field-based validation of a tactile navigation device. IEEE Transactions on Haptics, 3(2), 78-87.

Erp, J. V. (2001). Tactile navigation display. In Proceedings of the first international workshop on Haptic Human-Computer interaction (pp. 165-173). London, UK: Springer-Verlag.

Erp, J. V., Veen, H. A., Jansen, C., \& Dobbins, T. (2005). Waypoint navigation with a vibrotactile waist belt. ACM Transactions on Applied Perception, 2 $106-117$.

Estrin, D. L. (2010). Participatory sensing: applications and architecture. In Proceedings of the 8th international conference on Mobile systems, applications, and services (pp. 3-4), MobiSys '10. New York, NY, USA: ACM.

Flintham, M., Benford, S., Anastasi, R., Hemmings, T., Crabtree, A., Greenhalgh, C., et al. (2003). Where on-line meets on the streets: Experiences with mobile mixed reality games. In Proceedings of the SIGCHI conference on Human factors in computing systems, CHI '03 (pp. 569-576). New York, NY, USA: ACM.

Foo, P., Warren, W. H., Duchon, A., \& Tarr, M. J. (2005). Do humans integrate routes into a Cognitive Map? Map - Versus Landmark-Based Navigation of Novel Shortcuts. Journal of Experimental Psychology: Learning, Memory \& Cognition, 31(2), 195-215.

Golledge, R. G. (1999). Wayfinding behavior: Cognitive mapping and other spatial processes. JHU Press.

Heikkinen, J., Olsson, T., \& Vanen-Vainio-Mattila, K. (2009). Expectations for user experience in haptic communication with mobile devices. In Proceedings of the 11th international conference on Human-Computer Interaction with mobile devices and services (pp. 28:1-28:10) MobileHCI '09. New York, NY, USA: ACM.

Hoggan, E., \& Brewster, S. A. (2010). Crosstrainer: Testing the use of multimodal interfaces in situ. In Proceedings of the 28th international conference on Human factors in computing systems (pp. 333-342). CHI '10. New York, NY, USA: ACM.

Holland, S., Morse, D. R., \& Gedenryd, H. (2001) Audio GPS: Spatial audio in a minimal attention interface. In 3rd International Workshop on $\mathrm{HCI}$ with Mobile Devices (pp. 28-33).

Jacob, R., Mooney, P., Corcoran, P., \& Winstanley, A. C. (2010). Haptic-gis: Exploring the possibilities, November 2010 (Vol. 2, pp. 13-18). New York, NY, USA: ACM.

Jacob, R., Mooney, P., \& Winstanley, A. C. (2011), Guided by touch: Tactile pedestrian navigation. In Proceedings of the 1st International workshop on Mobile locationbased service, MLBS ‘11 (pp. 11-20). ACM, New York, NY, USA.

Jacob, R., Mooney, P., Corcoran, P., \& Winstanley, A. C. (2011). Model for hapticassisted pedestrian navigation mobile applications. In Proceedings of the 11th International Conference on GeoComputation. UCL, London, England.

Jacob, R., Shalaik, B., Winstanley, A. C., \& Mooney, P. (2011). Haptic feedback for passengers using public transport. In H. Cherifi, J. Zain, \& E. El-Qawasmeh (Eds.), The international conference on digital information and communication technology and its applications (DICTAP), volume Part I of CCIS 166 (pp. 24-32). Heidelberg: Springer.

Jacobson, R. (2002), Representing spatial information through multimodal interfaces. In Information visualisation, 2002: Proceedings. Sixth international conference on (pp. 730-734).

Klippel, A., Hansen, S., Richter, K., \& Winter, S. (2009). Urban granularities - A data structure for cognitively ergonomic route directions. Geoinformatica, 13, 223-247.

Kuipers, B. (1978). Modeling spatial knowledge. Cognitive Science, 2, 129-153.

Lee, C. -L., Cheng, Y. -M., Lee, D. M. -W. Lin, Chen, L. -C., \& Sandnes, F. E. (2009), The exploration of non-visual interaction for social proximity applications in a Taiwanese night market. In Proceedings of the 21st annual conference of the Australian Computer-Human interaction special interest group: Design: Open 24/7. OZCHI '09 (pp. 389-392). New York, NY, USA: ACM.

Li, K. A., Sohn, T. Y., Huang, S., \& Griswold, W. G. (2008), Peopletones: A system for the detection and notification of buddy proximity on mobile phones. In Proceedings of the 6th international conference on Mobile systems, applications, and services, MobiSys '08 (pp. 160-173). ACM, New York, NY, USA.

Mata, F., Jaramillo, A., \& Claramunt, C. (2011). A mobile navigation and orientation system for blind users in a metrobus environment. In Proceedings of the 10th international conference on Web and wireless geographical information systems, W2GIS'11, (pp. 94-108). Berlin, Heidelberg: Springer-Verlag.

May, A. J., Ross, T., Bayer, S. H., \& Tarkiainen, M. J. (2003). Pedestrian navigation aids: information requirements and design implications. Personal and Ubiquitous Computing, 7, 331-338.

Moussaid, M., Perozo, N., Garnier, S., Helbing, D., \& Theraulaz, G. (2010). The walking behaviour of pedestrian social groups and its impact on crowd dynamics. PLoS ONE, 5(4).

Nelson, H. R. (1982). National Adult Reading Test (NART): Test manual. Windsor: NFER-Nelson.

O'Keefe, J., \& Nadel, L. (1978). The hippocampus as a cognitive map. Oxford: Clarendon Press.

Paneels, S., \& Roberts, J. (2010). Review of designs for haptic data visualization. IEEE Transactions on Haptics, 3(2), 119-137.

Parush, A., Ahuvia, S., \& Erev, I. (2007). Degradation in spatial knowledge acquisition when using automatic navigation systems. In S. Winter, M. Duckham, L. Kulik, \& B. Kuipers (Eds.), Spatial information theory: Lecture notes in computer science (Vol. 4736, pp. 238-254). Berlin/Heidelberg: Springer.

Pascale, M., Mulatto, S., \& Prattichizzo, D. (2008). Bringing haptics to second life for visually impaired people. In Proceedings of the 6th international conference on haptics: Perception, devices and scenarios, EuroHaptics '08 (pp. 896-905). Berlin, Heidelberg: Springer-Verlag. 
Pielot, M., \& Boll, S. (2010). Tactile wayfinder: Comparison of tactile waypoint navigation with commercial pedestrian navigation systems. 6030, pp. 76-93.

Pielot, M., Poppinga, B., \& Boll, S. (2010). Pocketnavigator: Vibro-tactile waypoint navigation for everyday mobile devices. In Proceedings of the 12th international conference on Human computer interaction with mobile devices and services, MobileHCI '10 (pp. 423-426). New York, NY, USA: ACM.

Reitan, R. (1955). The relation of the trail making test to organic brain damage. Journal of Consulting Psychology, 19(5), 393-394.

Reitan, R. M. (1958). Validity of the Trail Making Test as an indicator of organic brain damage. Perceptual Motor Skills, 8, 271-276.

Robinson, S., Eslambolchilar, P., \& Jones, M. (2009). Evaluating haptics for information discovery while walking. In Proceedings of the 23rd British $\mathrm{HCl}$ Group Annual Conference on People and Computers: Celebrating People and Technology, BCS-HCI '09 (pp. 93-102). Swinton, UK, UK: British Computer Society.

Robinson, S., Eslambolchilar, P., \& Jones, M. (2009). Sweep-shake: Finding digital resources in physical environments. In Proceedings of the 11th Internationa Conference on Human-Computer Interaction with Mobile Devices and Services, MobileHCI '09 (pp. 12:1-12:10). New York, NY, USA: ACM.

Robinson, S., Jones, M., Eslambolchilar, P., Smith, R. M., \& Lindborg, M. (2010). “I did it my way": Moving away from the tyranny of turn-by-turn pedestrian navigation. In MobileHCI '10: Proceedings of the 12th international conference on Human computer interaction with mobile devices and services (pp. 341-344), New York, NY, USA.

Roche, R. A. P., Mangaoang, M. A., Commins, S., \& O’Mara, S. M. (2005). Hippocampal contributions to neurocognitive mapping in humans: A new model. Hippocampus, 15, 622-641.
Shepard, R. N., \& Metzler, J. (1971). Mental rotation of three-dimensional objects. Science, 171, 701-703.

Sjölinder, M. (1998). Spatial cognition and environmental descriptions. Institute of Navigation in Electronic Spaces/SICS.

Strachan, S., Eslambolchilar, P., Murray-Smith, R. Hughes, S., \& O'Modhrain, S. (2005) Gpstunes: Controlling navigation via audio feedback. In Proceedings of the 7th international conference on Human computer interaction with mobile devices E' services, MobileHCI'05 (pp. 275-278). New York, NY, USA: ACM.

Tavakoli, M., Patel, R., \& Moallem, M. (2005). Haptic interaction in robot-assisted endoscopic surgery: A sensorized end effector.

Tversky, B. (2000). Levels and structure of spatial knowledge. In R. Kitchin \& S. Freundschuh (Eds.), Cognitive mapping: Past, present and future (pp. 24-43). London: Routledge.

Whitney, M., \& Richter Lipford, H. (2011). Participatory sensing for community building. In Proceedings of the 2011 annual conference extended abstracts on Human factors in computing systems, CHI EA '11 (pp. 1321-1326). New York, NY, USA.

Wikitude (2012). <http://www.wikitude.com/drive> Accessed July 2012.

Williamson, J., Robinson, S., Stewart, C., Murray-Smith, R. Jones, M., \& Brewster, S. (2010). Social gravity: A virtual elastic tether for casual, privacy-preserving pedestrian rendezvous. In Proceedings of the 28th international conference on Human factors in computing systems, CHI '10 (pp. 1485-1494). New York, NY, USA: ACM.

Zelek, J. S. (2005), Seeing by touch (haptics) for wayfinding. In International congress series, 1282:1108-1112, April 2005. 